\title{
NEGOCIAÇÃO COLETIVA EM SAÚDE DO TRABALHADOR segurança em máquinas injetoras de plástico
}

\author{
Leonardo Mello e Silva
}

Resumo: O texto aborda a convenção coletiva sobre segurança em máquinas injetoras de plástico, centrando o foco no processo de negociação entre os representantes classistas. Esse processo é situado como uma inovação na relação entre capital e trabalho no Brasil, devido ao seu caráter de entendimento direto, bipartite, entre as partes. Por fim, apontam-se os itens concretos da convenção que podem ter desdobramentos críticos em termos da cultura corporativa nas relações de trabalho.

Palavras-chave: negociação coletiva em saúde do trabalho; relações de trabalho; relações industriais.

\begin{abstract}
This essay considers collective bargaining with respect to the safety of plastic- injecting machinery, focusing on the negotiating process between the traditional parties. This process emerges as an innovative approach to management-employee relations in Brazil, due to the direct, bipartite dialogue between representatives of both sides. Lastly, specific aspects of the bargaining process are highlighted for their potential to bring about significant developments in terms of corporate culture and labor relations.

Key words: collective bargaining for occupational health; labor relations; industrial relations.
\end{abstract}

$\mathrm{O}$ $\mathrm{s}$ anos 90 significaram um influxo no movimento sindical no que se refere à maneira de encarar a negociação coletiva. A sua parte mais combativa, associada ao "novo sindicalismo" e representada pela Central Única dos Trabalhadores (CUT), passou a incorporar uma postura mais propositiva nos conflitos com o seu oponente de classe, e isso em vários âmbitos da pauta da relação capital-trabalho, incluindo aí a saúde do trabalhador.

Historicamente, o momento que marcou a passagem de um sindicalismo de confronto para aquele chamado ativopropositivo foi a experiência das câmaras setoriais, ${ }^{1}$ quando ficou demonstrado, para a opinião pública, os analistas e sobretudo os negociadores empresariais, que os trabalhadores tinham propostas consistentes e razoáveis dentro da ordem social vigente, capazes de gerar uma política industrial e de desenvolvimento, começando pelo setor de atividade e estendendo-se para o conjunto da economia.

A capacidade de definir uma agenda de questões que iam do particular ao geral, dos problemas do chão-de-fábrica a estratégias de investimento de grandes grupos econômicos, passando pelos salários, infundiu uma percepção entre os atores do mundo do trabalho de que uma modalidade finalmente nova de relacionamento entre as classes sociais modernas tinha-se estabelecido na sociedade brasileira, sepultando o corporativismo que havia por tanto tempo contaminado as nossas relações profissionais. $\mathrm{O}$ traço mais característico que permitia um tal diagnóstico era sem dúvida o fato de que os atores coletivos tinham chegado a acordos importantes através de negociação direta, sem a interferência controladora e inibidora do Estado. A negociação tripartite tomava a presença estatal, nas câmaras setoriais, muito mais como um contratante, de peso equivalente aos demais, como capital e trabalho, do que como "árbitro" ou fonte de legitimidade (Oliveira et al., 1993).

É nesse pano de fundo que se precisa compreender os movimentos de negociação coletiva na área de saúde do trabalhador, do qual o Acordo (posteriormente convertido em Convenção) sobre Prevenção de Acidentes em Máquinas Injetoras de Plástico é um caso bem típico. O presente artigo terá o propósito de expor uma tal idéia a partir do acompanhamento do referido Acordo (depois Convenção), extraindo dessa narrativa os elementos teoricamente mais interessantes do ponto de vista das relações de trabalho no Brasil. 


\section{O FOCO DO PROBLEMA}

Os acidentes com máquinas injetoras de plástico constituem um problema sério de saúde pública. As informações disponíveis são eloqüentes a esse respeito: no município de São Paulo, o setor plástico é um dos que mais contribuem para a triste estatística dos acidentes graves com mutilações dos membros superiores. Segundo dados do Centro de Reabilitação Profissional do INSS de São Paulo, para 1992, coletados pela Secretaria de Saúde e Meio Ambiente do Sindicato dos Trabalhadores nas Indústrias Químicas, Farmacêuticas, Plásticas e Similares de São Paulo, cerca de $78 \%$ dos casos de doenças e acidentes graves no setor são provocados por máquinas, sendo que, desse total, a metade deve-se a prensas injetoras. A listagem dos agravos recolhidos pelos diagnósticos do CRP/INSS de São Paulo mostra que a mutilação da mão direita e a da mão esquerda respondem, juntas, por $70 \%$ daqueles agravos. Em seguida, vêm seqüela-fratura de membro superior e seqüela-fratura de membro inferior, elevando o percentual para $75 \%$ do total dos diagnósticos. Outra característica importante revelada pela mesma fonte é que os acidentes ocorrem principalmente entre os jovens, na faixa de 18 a 25 anos (41\%), e em quase $40 \%$ dos casos no período imediatamente após a contratação do trabalhador, na fase dita de "experiência", isto é, até três meses. O nível de escolaridade entre a população acidentada situa-se majoritariamente na faixa entre a $1^{\underline{a}} \mathrm{e}$ a 4a séries do ensino fundamental e as funções atingidas dividem-se entre aquelas de baixa qualificação (ajudante geral) e operadores de máquina, conformando ambos $86 \%$ de todas as ocupações dos acidentados (Coelho, Vilela e Tsunabi, 1996:169-173).

Essas indicações já seriam suficientes para justificar uma intervenção pública orientada especificamente para esse tipo de realidade. A novidade é que tal intervenção foi tentada e levada a cabo não pelos organismos estatais funcionalmente implicados, mas pelos próprios representantes classistas, o que configura um fato sociologicamente relevante, como se verá a seguir.

\section{O ACORDO}

\section{Antecedentes}

Desde 1992 vem-se tentando chegar a um acordo entre os principais agentes da indústria usuários de máquinas injetoras de plástico. A preocupação portanto é longeva e a riqueza do processo de negociação vem principalmente do protagonismo assumido pela representação dos trabalhadores, até então um ator coletivo considerado subalternamente entre os ditos principais "agentes". É importante ressaltar esse procedimento pioneiro que situa historicamente a predisposição à negociação e ao diálogo por parte dos sindicatos - mesmo aqueles considerados de tendência mais aguerrida e confrontacionista com o capital -, como uma corrente que não se dilui na cultura gerencial da "parceria" e do "ganha-ganha", muito espalhada também, nessa época, no interior das empresas.

Histórico do Acordo - O canal de negociação foi construído aos poucos. Em 1993 ocorreu, no Sindicato dos Plásticos de São Paulo, ${ }^{2}$ o Seminário "Plásticos do Futuro", em que apresentado um balanço da situação dos acidentes e dos acidentados. No primeiro semestre de 1994, aconteceu, no Sindicato dos Trabalhadores em Indústrias Químicas, Farmacêuticas e Similares de São Paulo, o I Seminário sobre Máquinas Injetoras. Já nessa época houve os encontros do Grupo de Trabalho (GT) no 8 da câmara setorial do complexo químico, sobre saúde e meio ambiente. Os atores eram, em boa parte, os mesmos. Como se verá a seguir, o fórum representado pelo GT da câmara setorial de certa forma amplificou o espaço já existente de discussão sobre as máquinas injetoras.

$\mathrm{O}$ sindicato dos trabalhadores químicos e farmacêuticos de São Paulo possuía, por essa época, uma assessoria na área de saúde e meio ambiente bastante ativa, com um acúmulo de conhecimento razoável sobre o problema não só das máquinas injetoras, mas também do benzeno, amianto e mercúrio, por exemplo. Foi essa especialização que permitiu, entre outras coisas, o reconhecimento por parte do contendor, no caso, a associação patronal (Sindiplast e Abiplast ${ }^{3}$ ), pois mostrava que o perfil da negociação tinha se modificado em relação aos tempos do padrão chamado "porta-de-fábrica", em que os sindicatos postavam o carro de som diante das empresas e gritavam palavras-de-ordem, porém não tinham conhecimento do que se passava verdadeiramente em seu interior. Essa radicalidade de fora, associada à fragilidade de dentro, expunha, na verdade, a grande dificuldade do sindicalismo brasileiro em interferir no processo de trabalho, e se traduz organizativamente na pouca implantação das chamadas "organizações por local de trabalho" (OLTs). As próprias Cipas, enquanto instrumentos de prevenção de acidentes e de controle das situações de risco no trabalho, deveriam funcionar como uma OLT, o 
que é inclusive incorporado pela Convenção em sua cláusula 5a (Fundacentro, 2001:9).

A redação final do primeiro acordo é de março de 1995. Em setembro do mesmo ano, o então Acordo sobre Máquinas Injetoras de Plástico converteu-se em uma Convenção Coletiva. Essa primeira convenção estabeleceu as bases para uma transição na substituição do maquinário obsoleto ou na adaptação de dispositivos de segurança. Tais bases diziam respeito sobretudo aos prazos para aquela substituição, bem como aos critérios de cobertura, incidindo primeiro sobre as grandes empresas, em tese com maior margem para arcar com os custos do investimento, e em seguida sobre as médias e pequenas.

A cláusula 2a da Convenção estabelece que as máquinas usadas não poderão ser postas à venda sem os dispositivos de segurança previstos na mesma Convenção. Ela tem o propósito de evitar a comercialização em um tipo de mercado secundário de máquinas injetoras que poderiam alimentar determinadas empresas a tentar uma economia de custos "suja". Como a existência de micro e pequenas empresas no setor plástico não é incomum, esse item termina por funcionar como uma rede protetora à tentação de estender a precarização sempre para o elo mais fraco na relação interfirmas. Fica evidente que o acordo não pode ficar circunscrito a uma interpretação estritamente técnica, seja em termos do desenho e da engenharia concernidos, seja em termos de prevenção e do projeto ergonômico: ele envolve necessariamente conseqüências sociais e econômicas. Nesse sentido, houve a necessidade de mobilizar novos atores, como o BNDES e o Sindimaq (Sindicato Nacional das Indústrias de Máquinas); o primeiro regulando a concessão de benefícios fiscais para empresas que estejam respeitando a Convenção; o segundo administrando a aplicação da norma entre os seus representados, sendo que o setor plástico é apenas uma parcela dessa população. O BNDES entrou como instituição interveniente/anuente (cláusula 17aㅗ, Fundacentro, 2001) na Convenção não só como um reconhecimento da implicação técnico-econômica da questão, mas também como uma demonstração prática de indução, ainda que limitada, das escolhas de investimento associadas a objetivos sociais definidos pelos atores interessados.

Entre um e outro formato - Acordo e Convenção - há mais do que uma filigrana terminológica: embora o conteúdo não tenha basicamente se modificado em sua definição quanto aos requisitos de segurança, a Convenção expressa o reconhecimento político do seu caráter de contratação coletiva, deslocando-se de uma inspiração tripar- tite para outra, bipartite. De fato, na Convenção operouse uma espécie de hierarquização dos agentes, definindose as figuras dos signatários principais, dos demais signatários e, por fim, dos intervenientes/anuentes. No primeiro bloco estavam, do lado do trabalho, a Confederação Nacional dos Químicos (CNQ-CUT) e a Federação Estadual dos Trabalhadores nas Indústrias Químicas e Farmacêuticas (àquela altura, sem filiação a nenhuma central sindical); e, do lado do capital, o Sindiplast. O segundo bloco contemplava 35 entidades, todas sindicatos de trabalhadores do Estado de São Paulo ligados ao complexo químico. No terceiro bloco, os intervenientes/anuentes eram a Delegacia Regional do Trabalho de São Paulo (DRTSP), a Fundacentro, o Diesat (Departamento Intersindical de Estudos e Pesquisas de Saúde e dos Ambientes de Trabalho), o Ministério Público, a Secretaria de Estado de Relações de Trabalho, o Centro de Referência em Saúde do Trabalhador, ligado à Secretaria de Saúde, associações patronais tais como a Abiplast e a Abimaq (Associação Brasileira da Indústria de Máquinas e Equipamentos), além das centrais sindicais - sempre lembrando que a abrangência do acordo é estadual. Hoje, em sua versão proposta para o biênio 2002-04, a figura dos intervenientes/ anuentes cai da Convenção.

A diferença entre o Acordo e a Convenção é que, ao definir os interlocutores como representantes classistas em primeiro plano, o efeito produzido foi o de uma verticalização setorial, isto é, capital e trabalho postos frente a frente e levando em conta seus interesses conflitantes na matéria deveriam responsabilizar-se por uma saída consensual para os seus problemas, sem o guarda-chuva do poder público. No fundo, eles estariam produzindo uma norma. Conquanto um exemplo bastante pontual saído do campo da saúde do trabalhador, o acordo sobre máquinas injetoras de plástico é indicação de um procedimento que se situa no diapasão das lutas dos movimentos sociais pela democratização da sociedade brasileira e é, nesse sentido, uma inovação, produto de uma seqüência de interações consecutivas entre atores organizados.

\section{A Convenção como Modalidade de Contratação Coletiva}

Um dos temas recorrentes no debate sobre modernização das relações de trabalho é a contratação coletiva. Bandeira histórica do sindicalismo nascido da crítica ao modelo estatal-corporativo, a contratação coletiva de trabalho obedece a variações que seguem as tradições na- 
cionais de relações industriais: de um padrão descentralizado e baseado nas profissões até um padrão vertical e articulado. É esse último que fornece a inspiração para o sindicalismo brasileiro atual.

Uma das funções da contratação coletiva nacional e articulada é a de operar um balanceamento entre regras de abrangência geral e aquelas que se referem a uma realidade particular de ramo, de atividade ou de situação geográfica, tendo sempre como orientação de base a irredutibilidade de direitos e vantagens. Dessa forma ela pode preservar o âmbito local, quando esse último significar um acréscimo ao patamar geral, e ao mesmo tempo evitar a desregulação completa, instituindo o princípio do "cada caso um caso".

O Geral e o Particular - A convenção, nesse sentido, preenche uma função análoga à da contratação coletiva. Ela é, aliás, uma modalidade dessa contratação. Inicialmente concebida como uma convenção de âmbito estadual, ela se expande para o setor plástico em outras praças, acarretando com isso o mesmo tipo de problema posto pela contratação coletiva: a compatibilização de um parâmetro negocial saído de uma realidade em que os representantes classistas estão em um estágio bem adiantado de interação e conflito (São Paulo) para outro em que carece qualquer prática argumentativa nesse âmbito e vigora o velho estilo truculento do patronato. Ao conduzir o estoque de relações sociais que suportam capital e trabalho do ponto mais desenvolvido para o menos desenvolvido, os sujeitos coletivos acabam encarnando, inadvertidamente, um papel civilizatório, pois contribuem para a disseminação da modernização das relações de trabalho em um ambiente originalmente avesso a mudanças.

As modificações normativas operadas pela Convenção atestam essa trajetória, embora aparentemente possam soar como um recuo. Na Convenção inicial, as chamadas cláusulas sociais (estabilidade, recusa da culpabilidade do acidentado) estavam inseridas em seu interior; hoje elas se encontram anexas, na forma de um "Termo Aditivo". Esse expediente permite tornar o acordo palatável para os interlocutores patronais de Estados da federação onde as cláusulas sociais causam o temor da incorporação de benefícios e direitos que eles não poderiam bancar. O "anexo" passa a ser objeto de negociação se e quando a correlação de forças em uma região assim o permitir, enquanto a questão central era impedir que as cláusulas sociais funcionassem como "amarras" para a expansão do acordo para outros Estados. Do ponto de vista dos trabalhadores do
Sudeste, onde o piso salarial da categoria é superior em pouco mais de 1/3 entre São Paulo e Bahia, por exemplo, além da ocorrência de distribuição de Participação nos Lucros e Resultados (PLR), o perigo de estabelecer um mínimo negocial muito baixo estaria na possibilidade de rebaixamento de direitos e vantagens. Mais uma vez, essas diferenças só atestam, primeiro, a realidade de que o que se negocia na Região Sudeste não é o mesmo que se negocia na Região Nordeste e, segundo, que a flexibilidade da letra da Convenção obedece à lógica do contrato coletivo articulado.

\section{O Significado da Contratação e o Papel do Estado - O} papel do poder público no Acordo entra, no primeiro momento, de maneira mais ativa e, no segundo, de forma um pouco mais subsidiária, quando se torna Convenção. Uma parcela de técnicos da DRT-SP foi incitadora e facilitadora basicamente por conta de uma relação histórica de aproximação de alguns de seus quadros com os sindicatos de trabalhadores. Esse aspecto só se torna relevante dentro de uma perspectiva não-formalista na apreciação das posições dos atores sociais diante do acordo. Assim, o Estado não aparece como uma entidade monolítica, mas sim como um campo de forças em que são possíveis, em determinados momentos, alianças com parcelas da burocracia pública, marginalizando aqueles nichos menos simpáticos às demandas do lado do trabalho. É bom lembrar que, na mesma época (1993), como já foi mencionado, os encontros da câmara setorial do complexo químico (Mello e Silva, 1999) foram palco de movimentações convergentes entre membros tanto do Ministério da Saúde (então sob a administração de Jamil Haddad) quanto do próprio Ministério do Trabalho (então sob a administração de Walter Barelli) e lideranças do CNQ-CUT, a central sindical que naquele momento suportava os referidos encontros. Pode-se adiantar, inclusive, a interpretação de que a câmara setorial potenciou o acordo das máquinas injetoras (Coelho, Vilela, e Tsunabi, 1996:173-174) porque recolheu uma iniciativa que já existia, mas que tinha dificuldade em encontrar um canal e uma oportunidade de explicitação e de implementação, mobilizando os recursos políticos liberados com o conhecimento recíproco e a distensão dos ânimos, para infundir nova vida às tentativas de se chegar a um terreno comum na matéria.

Afirmar que o acordo tem uma feição contratualista por causa de seu formato bipartite não quer dizer, além disso, que o Estado deva estar ausente. Ao contrário, ele comparece em uma função reguladora, diferentemente do pa- 
pel impositivo e tutelar das relações de trabalho, associado ao corporativismo (Paoli, 1994). O caso particular das máquinas injetoras de plástico é um bom exemplo do desenrolar bem-sucedido de uma nova cultura negocial, não estando com isso eximido de problemas, conforme será visto mais adiante. Porém, é uma indicação alentadora das mudanças, o que é reconhecido em primeiro lugar pelos próprios agentes coletivos envolvidos: as associações patronais do setor e os sindicatos, se bem que com nuances. Enquanto o segmento patronal enxerga aí uma "flexibilização do processo de negociação coletiva, com a supervisão mas sem a imposição do Estado", ${ }^{4}$ os sindicatos identificam a própria negociação coletiva, concebida nos termos do contrato coletivo.

O fato, em primeiro lugar, de sua coordenação e administração ficarem a cargo dos contratantes é um indício de poder deliberativo efetivo. Em segundo lugar, devese frisar a instituição de uma Comissão Permanente de Negociação (CPN), considerada o "ponto alto" da Convenção, a qual prevê reuniões regulares todo o mês com o fim de avaliar a sua aplicação e zelar pelo seu cumprimento, inclusive com mecanismos de sanção e de regulamentação, como nos casos previstos da proposição de mediação e arbitragem (parágrafos 2o, 3e e 4o da cláusula 10aㅡ, Fundacentro, 2001:10).

Assim, a instância estatal comparece não mais como definidora da agenda das partes litigantes, nem como recurso último para o qual são transferidos os impasses, isto é, os tribunais. Isso é tanto mais adequado ainda na área de saúde, uma vez que a juridificação se refere sempre a um ato já consumado, o qual pode em tese ser bem definido e caracterizado, enquanto o acidente e o risco devem ser sempre evitados por meio da prevenção. Mas, de todo o modo, seria incorreto afirmar que o Estado simplesmente saiu de cena: a Fundacentro, órgão vinculado ao Ministério do Trabalho, participa como aplicador do curso de multiplicação ou de capacitação concebido pela CPN.

$\mathrm{O}$ curso terminou se convertendo em um instrumento original, uma vez que aborda até o detalhamento dos problemas envolvidos nas prensas injetoras, cobrindo uma área em que a legislação é insuficiente porque inespecífica. O curso possibilita o credenciamento de profissionais técnicos da própria empresa (que podem ser engenheiros, médicos, cipeiros, operários, etc.), o que a desobriga de contratar auditorias ou arbitragens externas, resultando em economia de custos. Os cursos são rápidos, de três dias no máximo (18hs), mas constam de apostilas e avaliação. Eles acabam gerando, por outro lado, um efeito inespera- do: a autonomia da CPN de certa maneira abala o orgulho profissional dos engenheiros de segurança do trabalho, que encaram o treinamento fornecido pela Comissão, via Fundacentro, como uma espécie de "afronta" à sua formação.

Desde o início, aliás, o acordo subordinou o aspecto técnico ao político e esse é um elemento não negligenciável porque expressa a vontade de se chegar à resolução efetiva do problema em questão - a redução dos acidentes -, mesmo tendo em conta o passado conflitivo dos atores. Demonstra portanto que, quando essa vontade prevalece, os argumentos técnicos aparentemente imperativos deixam de ser determinantes para o deslanchar do processo negocial. Foi o que se observou quando sindicalistas e representantes patronais acordaram acerca dos princípios gerais necessários e somente depois incorporaram os engenheiros e mobilizaram a ABNT. ${ }^{6} \mathrm{Na}$ verdade, de certa forma os contratantes tomaram para si a responsabilidade de encontrar respostas para itens práticos que se interpunham ao desenvolvimento do processo no momento em que se viram diante da fatalidade de que não havia, na documentação disponível, uma norma técnica que definisse categoricamente o que seria "mecanismo de proteção". Essa carência acabou ensejando uma pesquisa sobre precedentes em outros países como França, Itália e EUA. ${ }^{7}$ Não foi utilizado aqui o velho expediente de delegar o assunto para um órgão burocraticamente circunscrito; ao contrário, os atores foram, autonomamente, até onde foi possível ir na matéria.

Um Caminho para a "Flexibilização de Direitos"? De fato, o elemento contratualista do acordo reside aqui na medida em que pressupõe o caráter autônomo das decisões. Por outro lado, desloca a visão jurisdicista que geralmente prevalece nos assuntos de saúde do trabalhador, como se viu acima, quando os impasses são encaminhados para o DRT e o Ministério Público, no que tange tanto à fiscalização quanto à punição, com abertura de processo, etc. Ao enfatizar a responsabilidade dos atores, o acordo contribui para uma resignificação das próprias entidades públicas. Aqui é preciso estar atento muito mais às disposições do que aos resultados, pois são as primeiras que dão sustentabilidade à prática negocial das lideranças e àquilo que aparece na superfície como postura "ativa-propositiva" ou, ainda, em certas leituras, como social-democratização do movimento sindical. A Convenção sobre Máquinas Injetoras de Plástico talvez seja um grão de inovação em meio a um deserto de permanência 
corporativa. Mas ganha coerência junto a outras iniciativas, como as câmaras setoriais, a que se fez referência anteriormente.

A formatação de uma mesma linguagem ${ }^{8}$ entre patrões e empregados identifica a possibilidade de um entendimento, isto é, do estabelecimento de regras, e não necessariamente de consenso. Há uma diferença grande entre a busca de um terreno comum e a renúncia das diferenças e do conflito. Nas palavras de um negociador importante do acordo, da Abiplast: "na negociação não se esconde o conflito mas se procura dar uma solução ao conflito". ${ }^{9}$ É um tal tipo de disposição que confere ao acordo sobre máquinas injetoras um significado importante para a apreciação mais ampla das relações de trabalho no Brasil.

Com respeito ao treinamento, é importante ressaltar que a Convenção não assegura exclusividade de prestação de serviço à Fundacentro; ao contrário, o modelo procura ser pluralístico, de tal maneira que outras instituições estão habilitadas a ministrar o curso de multiplicação de especialistas em segurança de máquinas injetoras. Tais instituições variam do Sesi/Senai até a Federação de Trabalhadores em Indústrias Químicas do Estado de São Paulo (hoje associado à Força Sindical mas no momento do Acordo, sem filiação a nenhuma central sindical), passando pelo Diesat, escolas privadas e o próprio Sindicato dos Trabalhadores em Indústrias Químicas, Plásticas e Farmacêuticas de São Paulo (vinculado à CUT), onde o Acordo foi originalmente gestado. Assim, se a Convenção, por um lado, avança no sentido da descentralização e contratualização das relações de trabalho, por outro, corre o ris co de fato de converter o âmbito de intervenção dos atores institucionais em um "negócio", tal como exemplificado no caso da habilitação de multiplicadores. O mesmo raciocínio se aplica à arbitragem, prevista na $\mathrm{CPN}$ em pelo menos duas ocasiões: em caso de acidente, para o levantamento das causas de (in)segurança, as quais podem variar entre a falta de dispositivos bloqueadores nas máquinas até a carência de treinamento por parte dos operadores, e em caso de indenizações (cláusula 10a). Com respeito ao primeiro caso, a CPN tem o poder inclusive de negociar a situação do trabalhador acidentado no chamado "Fórum da CPN", ao invés de remetê-lo à Justiça do Trabalho, ganhando celeridade (em duas ou em até uma semana o caso pode ser resolvido). Ali é possível, em tese, questionar determinadas aquisições estatutárias, tais como a garantia de estabilidade, em troca de outras vantagens. Nos exemplos concretos registrados até aqui foi possível observar um caso de negociação de direitos adquiridos e um outro de manutenção da cláusula da estabilidade para trabalhadores acidentados.

É evidente que essas alternativas correm o risco de engrossar o rol de dispositivos flexibilizadores nas relações de trabalho, especialmente em uma conjuntura em que as correntes desregulamentadoras na economia e na sociedade enfatizam a necessidade de sobrepor o negociado ao legislado (Santos, 2001). Com relação a essas objeções, o que se pode dizer é que o dado da modernização não carrega um destino preestabelecido: depende do sentido que lhe é conferido pelos atores coletivos e as classes sociais, isto é, se a linha-de-força predominante vai ser reforçadora do mercado ou, ao contrário, dos direitos sociais como parâmetro regulatório.

É importante ressaltar que a CPN detém o monopólio de emissão do "selo" capaz de habilitar as máquinas injetoras. Isso reforça mais ainda o seu poder institucional. O selo funciona como uma espécie de certificação da segurança das máquinas e é uma exigência após o treinamento efetuado por uma instituição privada, como aquelas citadas anteriormente. Nesse sentido, a CPN, ao avalizar o treinamento efetuado, se responsabiliza diante das empresas que contrataram o treinamento, das instituições e escolas que o praticaram e da opinião pública em geral. Esse papel desempenhado pela CPN não deixa de ser eminentemente público, embora não estatal. Também não se trata de substituir o Estado, mas sim de infundir um conteúdo participativo e, portanto, de democratizá-lo a partir da iniciativa cidadã, sendo que nesse caso tal iniciativa é a expressão de interesses coletivos, de classe. O DRT, por exemplo, não dispõe de estrutura e pessoal suficiente para fazer o treinamento de multiplicadores, mas possui cadeira cativa no interior da CPN. Nesse caso, o técnico tem de conhecer a norma específica para as máquinas injetoras de plástico, saída da Convenção, além do conhecimento sobre a legislação ordinária aplicável de forma geral.

A idéia de aproveitar um operador ou um profissional de segurança (médico, engenheiro ou técnico, por exemplo) da própria empresa como multiplicador obedece, além das razões econômicas, ao propósito de uma política de segurança do trabalho, na medida em que essa última pressupõe um diálogo permanente. Uma visão estritamente mercantil, ao contrário, não privilegia a construção de uma relação de confiança entre as partes, atendo-se aos resultados de curto prazo: é o que acontece com os treinamentos rápidos mas de qualidade duvidosa, comum nos cursos para cipeiros. É importante, portanto, que o multiplicador seja alguém que esteja pre- 
sente constantemente no chão-de-fábrica. O mesmo princípio vale para o pessoal de manutenção: também ele deve ser comprometido com o treinamento e a segurança das máquinas, embora possa não ter uma relação direta com ela. O caso de um acidente com um eletricista, ocorrido há cerca de seis anos, é exemplar: ao tentar desentupir o bico de uma injetora com o alicate, o trabalhador sofreu queimaduras que o desfiguraram seriamente. De forma análoga, os trabalhadores terceirizados não podem ser excluídos do processo: enfim, a idéia é que todos aqueles que tenham uma relação com a máquina injetora de plástico, mesmo não sendo operadores, devem estar contemplados pelo treinamento.

As várias versões da Convenção (bianuais) são objeto de negociação permanente, o que faz com que algumas cláusulas sejam acrescentadas ou suprimidas de acordo com a correlação de forças e as trocas recíprocas. A chamada "teoria do ato inseguro" para explicar os acidentes de trabalho estava contida na versão anterior da Convenção (cláusula 6aㅡ, Fundacentro, 2001) embora esteja ausente da proposta de redação para a versão mais atualizada, prevista para vigorar entre setembro de 2002 e setembro de 2004. Em compensação, a cláusula 12 a da versão anterior, que incluía a estabilidade para os acidentados, desaparece na última versão. A responsabilização do operador pelo acidente é motivo de uma batalha histórica movida contra essa concepção por parte da bancada sindical e pelos médicos do trabalho ligados à saúde do trabalhador, os quais a consideram como uma explicação inadequada e superada internacionalmente. Já os empresários relutam em aceitar a cláusula da estabilidade; tanto é verdade que os seus quatro parágrafos subseqüentes na Convenção de 1999 (Fundacentro, 2001:11) praticamente dissolviam a incondicionalidade do benefício, pois era criada uma série de brechas em que ele poderia ser suspenso. As cláusulas "polêmicas" foram assim transferidas para um "Termo Aditivo" à Convenção, a fim de serem negociadas separadamente, segundo as diversas realidades geográficas e regionais, conforme se fez referência anteriormente.

Novamente, esse é sem dúvida um aspecto ambíguo da contratação social, uma vez que concretamente ela pode estar negociando os chamados "direitos adquiridos" que foram incorporados na memória coletiva da classe trabalhadora. Sua forma "bipartite" passa a ser motivo de crítica, em que outros autores enxergam a virtude da autonomia e da liberdade de negociação. No entanto, ele expõe a capacidade de pressão política e de poder argumentativo tanto de um lado quanto de outro; força a alianças com a sociedade civil e mobiliza, enfim, a opinião pública a fim de fazer valer as idéias e interesses de cada um.

\section{A Importância de um Enfoque Preventivo}

Existe uma correlação positiva entre a interferência dos sindicatos na inclusão de cláusulas preventivas nos acordos coletivos de categoria - mesmo aqueles previstos pela legislação trabalhista - e a diminuição do número de acidentes de trabalho e doenças ocupacionais notificadas via CATs, ${ }^{10}$ pois, enquanto no setor industrial essas notificações acusam um decréscimo de 19,4\% entre 1997 e 1999, no mesmo período os setores de agricultura e serviços registraram um decréscimo de apenas $1,9 \%$ e 2,6\%, respectivamente. No setor industrial é possível encontrar a inclusão de cláusulas preventivas de saúde e segurança do trabalho em acordos coletivos de categoria, enquanto o mesmo não ocorre nos setores de agricultura e serviços (Dieese apud Cacciamali; Sandoval, 2000:39-40).

Um dos aspectos relevantes da Convenção é que ela expressa um acordo coletivo em saúde e segurança do trabalho com enfoque preventivo e não compensatório, isto é, aquele que visa agir apenas após consumado o acidente. Dessa forma, toda a processualística ligada ao ato do acidente, como multas, fiscalização e processos reparatórios de indenização ficaria minimizada em favor de ações que buscariam agir sobre as causas e não sobre os efeitos. Ao fazê-lo, os contratantes sociais vão descobrindo, através de um processo de aprendizagem recíproco, que as raízes da insegurança e sua fonte repousam na maior parte dos casos na própria organização do trabalho.

Enquanto o setor patronal enfatiza a desburocratização e a flexibilização da legislação, considerada uma "camisa-de-força" à livre negociação, o processo negocial na verdade transfere o marco regulatório para o campo da produção, ao invés de simplesmente eliminá-lo ou "enxugá-lo", pois, vistas as coisas de mais perto, a Convenção representa muito mais um movimento de criação normativa, dada a minúcia e o detalhamento a que ela se presta, do que de minimalismo e desregulação.

Isso acaba expondo, inadvertidamente ou não, uma faceta estrutural do sistema corporativista de relações de trabalho ainda vigente (Consolidação das Leis do Traba1ho): o de que, a despeito da grande quantidade de produção legislativa e de normatização estatutária, assim como da amplitude de sua cobertura, a base jurídica define um sujeito individual e não um sujeito coletivo como unidade dos contratos. Essa concepção fica seriamente abalroada 
com a consideração de itens de saúde coletiva e meio ambiente, pois as responsabilidades passam a ser tomadas necessariamente de uma perspectiva social: as condições de trabalho e a organização do processo produtivo.

Assim, o expediente bastante comum no ambiente da indústria de transformadores plásticos de fazer "gambiarras" para desativar dispositivos de segurança nas máquinas, a fim de alcançar maior produtividade (Coelho; Vilela; Tsunabi, 1996:169), passa a ser considerado uma questão ligada à saúde coletiva do ambiente de trabalho em seu conjunto, e não um problema associado à "decisão pessoal" do trabalhador, uma vez que reconhece os constrangimentos (relação desigual de poder entre empregador e empregado) que pesam sobre aquela decisão individual.

A contratação representada pela Convenção sobre Máquinas Injetoras de Plástico, ao mesmo tempo em que desregulamenta os preceitos da CLT, re-regulamenta segundo um novo patamar de direitos.

\section{BALANCO E RESULTADOS}

A Convenção já tem sete anos de vigência. Nesse tempo foram treinados no setor plástico, até 2001, 5.159 trabalhadores. Foram expedidos 3.350 selos, o que significa dizer que esse é o número de máquinas com os dispositivos de segurança adequados, no mesmo período.

As novidades formais da Convenção estão situadas exatamente em contraponto à CLT. Muitas já foram discutidas com algum pormenor acima. São elas:

- a não exigência de data-base. A "cultura da data-base" tem como corolário que a negociação só se dá uma vez por ano: "só negocia em novembro"; 11

- como consequiência do que precede, o estímulo a uma "negociação permanente", por oposição à prática de acumular e protelar as pendências até a data-base, quando então seriam resolvidos, supostamente, todos os problemas;

- prazo de vigência do acordo supera o previsto em lei: enquanto as negociações coletivas têm a duração de um ano, a convenção possui vigência de dois anos, podendose prorrogar por mais um ano;

- o estabelecimento de regras para garantir o cumprimento do acordo estipulado entre as partes envolvidas, o que dificulta o descumprimento da legislação, como acontece freqüentemente com a CLT;

- a solução dos conflitos é pela via da negociação direta, criando uma "cultura negocial", ao invés da remissão da solução de conflitos para a Justiça do Trabalho;
- a constituição de subcomissões por áreas geográficas ou por empresas, o que permite combinar um padrão geral ou "horizontal" com outro "vertical", sensível às especificidades regionais ou até mesmo ao nível mais desagregado e particularizado das empresas (parágrafo 1o da cláusula 4ํㅡ da Convenção, Fundacentro, 2001:8);

- recorrênca à "mediação" ou "arbitragem" nos casos de “impasses que venham a ocorrer" (Fundacentro, 2001:8);

- a Cipa, concebida como elo de ligação entre a CPN e o local de trabalho (cláusula 5a, Fundacentro, 2001:9) passa a ter acesso ao livro de Registro das Máquinas Injetoras, assim como aos manuais, laudos, avaliações e demais documentos referentes à máquina, além da possibilidade de checagem periódica delas. As Cipas passam a ter o direito de paralisar as máquinas quando for observada a existência de risco grave ou de máquinas sem dispositivo de segurança. Elas também passam a poder solicitar assessoria técnica ao sindicato, a entidades a ele vinculadas (por ex., Diesat e INST ${ }^{12}$ ) ou a instituições públicas (DRT, SUS, etc.), caso necessário. Aumenta o poder da Cipa, dando-lhe um caráter menos "oficialista" e permitindo que ela exerça o direito democrático à informação, tão importante para consolidar a capacidade de influência do movimento sindical nos assuntos referentes a mudanças e rearranjos no processo de trabalho (Bresciani, 1994). Caminha, portanto, no sentido de maior transparência na relação entre as partes, condição necessária para a construção de uma relação de confiança a médio e longo prazos, que busque perdurar para além de situações ad hoc. Ressalte-se que um tal nível de confiabilidade em uma contratação setorial é coerente com a busca de co-responsabilidade nas estratégias de gestão no interior das empresas. Como afirmou caracteristicamente o representante patronal: "todos têm responsabilidade em um trabalho participativo"; 13

- a CPN pode substituir a Justiça Comum no caso de indenização por acidente com injetoras de plástico. Ela tem o atributo de definir responsabilidade civil nesses casos e fixar indenização em primeira instância. Em outros casos, quando não houver acordo entre as partes, a CPN pode jogar o problema para a mediação (cláusula 10a), ao invés de remeter para a Justiça do Trabalho. Além desse papel de criação normativa, é ela quem credencia os cursos de capacitação e multiplicação em segurança de máquinas injetoras, oferecidos na Fundacentro;

- a obrigação de validação das decisões pelos dois lados - isto é, as cláusulas da Convenção - tem de valer para as duas partes, caso contrário leva ao descrédito: são as cha- 
madas "cláusulas quanto ao compromisso" - o que reforça a contratualidade da experiência.

\section{PERSPECTIVAS}

Neste texto foi exposto apenas o caso da Convenção Coletiva sobre Prevenção de Acidentes em Máquinas Injetoras de Plástico. Foi dada ênfase ao processo de negociação direta entre as partes, inserindo-o dentro de uma nova postura negocial, chamada "ativa-propositiva", acompanhando-se para isso a trajetória do Acordo até a Convenção. Ressaltou-se também a preocupação preventiva contida na Convenção, o que desloca o modelo vigente de fiscalização de acidentes, distante da realidade e atuando apenas após e raramente antes do ocorrido.

Outras iniciativas em outros setores e ramos de atividade certamente serão uma tendência daqui para a frente, mesmo com a ameaça de flexibilidade e desregulação pairando sobre a cabeça dos trabalhadores e suas entidades de representação. A marcha para o contrato coletivo de trabalho alimenta-se de iniciativas como essa: madura e circunstanciada, passando ao largo tanto do assistencialismo dos sindicatos quanto do intervencionismo estatal, dois lados de uma mesma moeda.

\section{NOTAS}

Agradeço a Oswaldo da Silva Bezerra, diretor do Sindicato dos Trabalhadores nas Indústrias Químicas, Plásticas, Farmacêuticas e Similares de São Paulo e do Diesat a disponibilização das informações fornecidas para a consecução deste trabalho, e à Fapesp pelo apoio.

1. As câmaras setoriais foram encontros organizados entre sindicatos de patrões e de empregados de cada setor de atividade econômica, tendo o Estado como parceiro e não como poder tutelar. Tiveram vigência entre 1992 e 1994 e possibilitaram, onde isso foi possível, estabelecer uma "agenda" dos principais problemas de cada setor, tendo como novidade a participação dos trabalhadores e a inserção de elementos de sua pauta, tais como emprego, salário, fim das terceirizações, qualificação da mão-de-obra, etc.

2. Posteriormente esse sindicato fundiu-se ao Sindicato dos Trabalhadores em Indústrias Químicas e Farmacêuticas e Similares de São Paulo.

3. Respectivamente, Sindicato da Indústria de Material Plástico do Estado de São Paulo; Associação Nacional da Indústria de Material Plástico.

4. Exposição do representante da Abiplast por ocasião do III Curso de Capacitação sobre Prevenção de Acidentes com Máquinas Injetoras de Plástico, na Fundacentro, em 15/03/1996.

5. Entrevista com membro da CPN, agosto de 2002.

6. Associação Brasileira de Normas Técnicas.
7. Exposição do representante da Abiplast por ocasião do III Curso de Capacitação sobre Prevenção de Acidentes com Máquinas Injetoras de Plástico na Fundacentro em 15/03/1996.

8. Esse discurso é muito comum entre profissionais de Recursos Humanos de grandes empresas, o que demonstra que o mesmo princípio válido para a negociação de atores coletivos na arena institucional é válido também para a relação entre gerência e trabalhadores no processo de trabalho.

9. Exposição do representante da Abiplast por ocasião do III Curso de Capacitação sobre Prevenção de Acidentes com Máquinas Injetoras de Plástico na Fundacentro em 15/03/1996.

10. Comunicação de Acidentes do Trabalho, centralizada no INSS.

11. Novembro é a data-base da categoria dos químicos. Fala da Dra. Elaine D'Avila Coelho, advogada representante da CNQ no III Curso de Capacitação sobre Prevenção de Acidentes em Máquinas Injetoras de Plástico, na Fundacentro, em 15/03/1996 (Mello e Silva, 1999:211).

12. Instituto Nacional de Saúde do Trabalhador.

13. Exposição do representante da Abiplast por ocasião do III Curso de Capacitação sobre Prevenção de Acidentes com Máquinas Injetoras de Plástico, na Fundacentro, em 15/03/1996.

\section{REFERÊNCIAS BIBLIOGRÁFICAS}

BRESCIANI, L.P. Da resistência à contratação: tecnologia, trabalho e ação sindical no Brasil. São Paulo: CNI/Sesi, Série Indústria e Trabalho, 1994.

CACCIAMALI, M.C.; SANDOVAL, S. Mediação e negociação em segurança e saúde do trabalho. São Paulo: Fipe/MTE, dez. 2000.

COELHO, E.D.; VILELA, R.A.G.; TSUNABI, W. Injeção de segurança no setor plástico. Convenção sobre segurança em máquinas injetoras. In: BONCIANI, M. (Org.). Saúde, ambiente e contrato coletivo de trabalho. Experiências em negociação coletiva. São Paulo: LTr, 1996. p.155-199.

FUNDACENTRO/ MTE. Convenção coletiva sobre prevenção de acidentes em máquinas injetoras de plástico. 2. ed. São Paulo, 2001.

MELLO E SILVA, L. A generalização difícil: a vida breve da câmara setorial do complexo químico seguida do estudo de seus impactos em duas grandes empresas do ramo. São Paulo: Annablume/Fapesp, 1999.

OLIVEIRA, F. de. O acordo das montadoras: quanto melhor, melhor. Novos Estudos Cebrap, São Paulo, n.36, p.3-7, jul. 1993.

PAOLI, M.C. Os direitos do trabalho e sua justiça: em busca das referências democráticas. Revista USP, São Paulo, n.21, p.101-115, mar./maio 1994.

SANTOS, R.C.B. dos. Empresários e a modernização das relações de trabalho. 2001. Dissertação (Mestrado em Sociologia) - Faculdade de Filosofia, Letras e Ciências Humanas da USP, São Paulo, 2001.

VILELA, R.A.G. Negociação coletiva e participação na prevenção de acidentes de trabalho. 1998. Dissertação (Mestrado em Saúde Coletiva) - Faculdade de Ciências Médicas, Unicamp, Campinas, 1998.

Leonardo Melloe S ilva: Professor do Departamento de Sociologia daFFLCH-USP(leomello@usp.br). 